Wilfrid Laurier University

Scholars Commons @ Laurier

\title{
Edaphic Specialization in Tropical Trees: Physiological Correlates and Responses to Reciprocal Transplantation
}

Jennifer L. Baltzer

Wilfrid Laurier University, jbaltzer@wlu.ca

Sean C. Thomas

University of Toronto

R. Nilus

University of Aberdeen

D.F.R.P. Burslem

University of Aberdeen

Follow this and additional works at: https://scholars.wlu.ca/biol_faculty

\section{Recommended Citation}

Baltzer, Jennifer L.; Thomas, Sean C.; Nilus, R.; and Burslem, D.F.R.P., "Edaphic Specialization in Tropical Trees: Physiological Correlates and Responses to Reciprocal Transplantation" (2005). Biology Faculty Publications. 11.

https://scholars.wlu.ca/biol_faculty/11

This Article is brought to you for free and open access by the Biology at Scholars Commons @ Laurier. It has been accepted for inclusion in Biology Faculty Publications by an authorized administrator of Scholars Commons @ Laurier. For more information, please contact scholarscommons@wlu.ca. 


\title{
EDAPHIC SPECIALIZATION IN TROPICAL TREES: PHYSIOLOGICAL CORRELATES AND RESPONSES TO RECIPROCAL TRANSPLANTATION
}

\author{
J. L. Baltzer, ${ }^{1,2,5}$ S. C. Thomas,${ }^{1}$ R. Nilus,${ }^{3,4}$ And D. F. R. P. Burslem ${ }^{4}$ \\ ${ }^{1}$ Faculty of Forestry, University of Toronto, 33 Willcocks Street, Toronto M5S 3 B3 Canada \\ ${ }^{2}$ Center for Tropical Forest Science-Arnold Arboretum Asia Program, Harvard University, 22 Divinity Avenue, \\ Cambridge, Massachusetts 02138 USA \\ ${ }^{3}$ Forest Research Center, Forestry Department, P.O. Box 1407, 90715, Sandakan, Malaysia \\ ${ }^{4}$ Department of Plant and Soil Science, University of Aberdeen, Cruickshank Building, St. Machar Drive, \\ Aberdeen AB24 $3 U U$ UK
}

\begin{abstract}
Recent research has documented the importance of edaphic factors in determining the habitat associations of tree species in many tropical rain forests, but the underlying mechanisms for edaphic associations are unclear. At Sepilok Forest Reserve, Sabah, Malaysian Borneo, two main soil types derived from sandstone (ridges) and alluvium (valleys) differ in nutrient and water availability and are characterized by forests differing markedly in species composition, structure, and understory light availability. We use both survey and reciprocal transplants to examine physiological adaptations to differences in light, nutrient, and water availability between these soil types, and test for the importance of resource-use efficiency in determining edaphic specialization. Photosynthetic surveys for congeneric and confamilial pairs (one species per soil type) of edaphic specialists and for generalists common to both soil types show that species specializing on sandstonederived soil had lower stomatal conductance at a given assimilation rate than those occurring on alluvial soil and also had greater instantaneous and integrated water-use efficiencies. Foliar dark respiration rates per unit photosynthesis were higher for sandstone ridge than alluvial lowland specialists. We suggest that these higher respiration rates are likely due to increases in photosynthetic enzyme concentrations to compensate for lower internal $\mathrm{CO}_{2}$ concentrations resulting from increased stomatal closure. This is supported by lower photosynthetic nitrogen-use efficiencies in the sandstone ridge specialists. Generalist species had lower water-use efficiencies than sandstone ridge specialists when growing on the drier, sandy ridgetops, but their nitrogen-use efficiencies did not differ from the species specialized to the more resource-rich alluvial valleys. We varied light environment and soil nutrient availability in a reciprocal transplant experiment involving two specialist species from each soil type. Edaphic specialist species, when grown on the soil type for which they were not specialized, were not capable of acclimatory shifts to achieve similar resource-use efficiencies as species specialized to that soil type. We conclude that divergent water-use strategies are an important mechanism underlying differences in edaphic associations and thus contributing to maintenance of high local tree species diversity in Bornean rain forests.

Key words acclimation; Borneo; edaphic association; multiple resource interactions; nitrogenuse efficiency; photosynthesis; reciprocal transplant experiment; tropical rain forest; water-use efficiency.
\end{abstract}

\section{INTRODUCTION}

Many factors contribute to the maintenance of tree species diversity in tropical rain forests, including distance- and density-dependent processes (Janzen 1970, Connell 1971, Wills et al. 1997), regeneration niche differentiation (sensu Grubb 1977), and aspects of chance and history that act to slow competitive exclusion (Poore 1968, Hubbell and Foster 1986, Hubbell 2001). In this paper we focus on another potential mechanism: habitat differentiation, particularly in relation to edaphic variables (Ashton 1969). The frequent

Manuscript received 31 March 2004; revised 23 March 2005 accepted 12 April 2005; final version received 26 May 2005. Corresponding Editor: M. J. Lechowicz.

${ }^{5}$ E-mail: jbaltzer@oeb.harvard.edu observation that many tropical tree species are distributed nonrandomly among edaphic patch types suggests that edaphic heterogeneity strongly influences species diversity in a given locality (Lescure and Boulet 1985, Webb and Peart 2000, Itoh et al. 2003). For example, Harms et al. (2001) found that $64 \%$ of 171 species in a 50-ha plot on Barro Colorado Island, Panama, showed significant habitat associations characterized by edaphic factors. Thomas (2003) categorized 820 species from the relatively uniform, mapped 50-ha plot in Pasoh, Malaysia, as generalists, edaphic specialists, and rare species, and estimated that $\sim 40 \%$ of the total species were edaphic specialists. Edaphic factors underlying these nonrandom distributions may include soil hydrological status (Becker et al. 1988, Thomas 2003), nu- 
trient availability (Gartlan et al. 1986, Baillie et al. 1987), and soil texture (Davies et al. 1998).

Several explanations for edaphic specialization in tropical forests have been proposed. Certain species have greater tolerance for high concentrations of trace metals, such as those found on ultramafic soils, which often leads to high numbers of rare and endemic species (reviewed in Proctor 2003). Biotic interactions such as herbivory and mycorrhizal associations may also contribute to tree species habitat associations (Coley and Barone 1996, Lee and Alexander 1996, Dickie et al. 2002, Fine et al. 2004). A third hypothesis is that species differ in ability to withstand conditions of limiting resource availability that vary among soil types (subsequently termed the "resource-use efficiency hypothesis"). We focus on this hypothesis, as species responses to differences in both water and nutrient availability have been implicated in the strong edaphic associations observed in Northern Borneo (Baillie et al. 1987, Itoh 1995, Palmiotto et al. 2004), the location of the present study. It is hypothesized that species occurring in resource-poor environments have been selected for traits that improve the efficiency with which they acquire and use the resource(s) in greatest limitation. Morphological or physiological adaptations allowing for improved efficiency in the use of a limiting resource(s) may provide growth and/or survival advantages over species not occurring there (Lambers and Dijkstra 1987, Lusk and Matus 2000). These differences in resource-use efficiency (RUE) may be particularly important to success in the resource-limited environment if availability of the limiting resource is temporally variable, resulting in periods of more severe shortage.

General models of the evolution of specialization predict that specialization on one resource will trade off against performance on other resources, and hence that resource generalists should show reduced competitive ability relative to specialist species when compared in the specialist's environment (Futuyma and Moreno 1988, Caley and Munday 2003). In the context of resource-use efficiency this assumes that a species associated with one habitat will not be capable of sufficient acclimation to achieve similar efficiency in the use of a limiting resource as specialists associated with the resource-limited habitat. Additionally, species from a more resource-rich habitat should show greater competitive ability given greater resource availability. From this model we also hypothesize that if differential RUE is contributing to habitat specialization, generalist species should not be capable of similar RUE as specialist species. More broadly, the RUE hypothesis can be viewed as an outcome of the costs associated with specialization such that adaptation to multiple environments compromises fitness in certain environments (Van Tienderen 1991, Dewitt et al. 1998, Relyea 2002).

Several studies have demonstrated changes in tree species rank given different resource availabilities (La- tham 1992, Gunatilleke et al. 1997, but see Palmiotto et al. 2004), suggesting that there may be trade-offs between abilities to tolerate scarcity of different resources. These differences may be partially driven by the ability of species tolerant of low levels of a particular resource to allocate less limiting resources so as to improve the efficiency of the uptake or use of the limiting resource (Bloom et al. 1985). Field et al. (1983) demonstrated that species occurring across a gradient of decreasing moisture had higher water-use efficiency (WUE), and that WUE was negatively correlated with nitrogen-use efficiency (NUE). Similarly, Wright et al. (2001) showed that species from lowrainfall sites had lower stomatal conductance but higher foliar nitrogen at a given photosynthetic rate than species from high-rainfall sites. At lower stomatal conductances, greater concentrations of photosynthetic enzymes, and thus nitrogen, are necessary to achieve similar photosynthetic rates, due to greater internal $\mathrm{CO}_{2}$ drawdown, resulting in a trade-off between WUE and photosynthetic nitrogen-use efficiency (PNUE) in drier environments (Wright et al. 2003). This provides a clearly defined physiological mechanism by which a plant sacrifices the efficient use of one resource for that of another more limiting resource.

The present study was conducted at the Sepilok Forest Reserve (SFR) located in northeastern Borneo, Malaysia. The reserve is topographically variable, with alluvial flats dissected by prominent sandstone ridges. The alluvial lowlands and sandstone ridges result in the differentiation of two floristic associations of lowland dipterocarp forest: sandstone hill and alluvial forests (Fox 1973). The close proximity of the two soil types undoubtedly results in considerable seed exchange, suggesting that these edaphic aggregations are not simply maintained by dispersal limitation. Soils on the alluvial flats are characterized by higher nutrient concentrations and water content in comparison to the sandstone soils (Table 1). In addition, the alluvial lowlands have a shallow water table and receive frequent freshwater flooding (Fox 1973). In contrast, the soils on the sandstone ridges are sandy and well drained, both characteristics that tend to lead to nutrient leaching and poor water storage capacity. Forest structural differences also result in differences in understory light environments between the two forest types (Table 1).

In the present study we examine which abiotic factor(s) (light, nutrient, and/or water availability) are most important in determining species habitat associations at SFR and test the importance of differential resource-use efficiency in predicting these associations. Specific hypotheses are as follows: (1) sandstone species are more conservative in their water use than alluvial specialists; (2) sandstone species exhibit greater photosynthetic nitrogen-use efficiencies; (3) given that either water or nutrients may be more limiting on the sandstone, there is a trade-off between nitrogen- and water-use efficiencies such that efficient use of the more 
TABLE 1. Mean site characteristics ( \pm SE) of sandstone hill (sandstone) and lowland dipterocarp (alluvial) gap and understory plots at Sepilok Forest Reserve.

\begin{tabular}{|c|c|c|c|c|}
\hline \multirow[b]{2}{*}{ Characteristic } & \multicolumn{2}{|c|}{ Gap } & \multicolumn{2}{|c|}{ Understory } \\
\hline & Sandstone & Alluvial & Sandstone & Alluvial \\
\hline \multicolumn{5}{|l|}{ Light $\left(\mathrm{mol} \cdot \mathrm{m}^{-2} \cdot \mathrm{d}^{-1}\right)$} \\
\hline Direct PPFD $\dagger$ & $10.94 \pm 0.14$ & $13.34 \pm 0.14$ & $2.90 \pm 0.18$ & $2.49 \pm 0.14$ \\
\hline Diffuse PPFD & $1.024 \pm 0.012$ & $1.595 \pm 0.012$ & $0.312 \pm 0.015$ & $0.315 \pm 0.012$ \\
\hline \multicolumn{5}{|c|}{ Water (gravimetric water content, g/g) $\ddagger$} \\
\hline Average (Apr-Mar) & $0.315 \pm 0.032$ & $0.375 \pm 0.027$ & $0.211 \pm 0.018$ & $0.278 \pm 0.016$ \\
\hline Minimum month & $0.248 \pm 0.032$ & $0.290 \pm 0.012$ & $0.166 \pm 0.023$ & $0.261 \pm 0.010$ \\
\hline \multicolumn{5}{|l|}{ Nutrients $(\mathrm{mg} / \mathrm{kg}) \ddagger$} \\
\hline $\mathrm{PO}_{4}$ & $0.88 \pm 0.35$ & $0.83 \pm 0.17$ & $2.12 \pm 0.87$ & $0.96 \pm 0.22$ \\
\hline $\mathrm{NO}_{3}$ & $5.51 \pm 0.73$ & $17.25 \pm 3.13$ & $5.15 \pm 1.44$ & $13.10 \pm 3.82$ \\
\hline $\mathrm{NH}_{4}$ & $20.1 \pm 4.8$ & $31.4 \pm 5.3$ & $23.22 \pm 3.12$ & $22.74 \pm 2.67$ \\
\hline Total P & $53.1 \pm 12.1$ & $281.1 \pm 22.4$ & $74.8 \pm 14.1$ & $343.7 \pm 70.5$ \\
\hline Total N & $1046.0 \pm 217.6$ & $2882.1 \pm 246.9$ & $1517.2 \pm 161.1$ & $3306.3 \pm 276.0$ \\
\hline
\end{tabular}

$\dagger$ Photosynthetic photon flux density.

$\ddagger$ All soil water and nutrient values from Dent (2004).

limiting resource comes at the expense of reduced efficiency in the use of the less limiting resource; (4) generalist species show lower RUE in comparison to specialists on either soil type; and (5) although species may show acclimation responses when grown on their nonnative soil type, alluvial specialists are genetically constrained such that they do not perform as sandstone specialists when grown on sandstone soils, and vice versa.

To address these hypotheses we used survey and experimental methods. We collected physiological survey data from congeneric or confamilial edaphic specialist species pairs to examine evolved resource-use strategies of species specialized to each soil type. RUE of generalist species was also compared to that of edaphic specialist species. Patterns of RUE for species occurring in their native habitats do not provide sufficient evidence to verify the RUE hypothesis, as these patterns can simply be a plastic response to the environment rather than representing adaptation to the environmental conditions (Reich et al. 2003). Species $\times$ environment interactions were therefore examined using a reciprocal transplant experiment (RTE) involving specialists from each soil type.

\section{Materials And Methods}

\section{Study area}

Sepilok Forest Reserve $\left(5^{\circ} 10^{\prime} \mathrm{N}, 117^{\circ} 56^{\prime} \mathrm{E}\right)$ is a Virgin Jungle Reserve managed by the Sabah Forestry Department and located in Northeastern Sabah, Malaysian Borneo. It is a coastal range forest fragment of 4294 ha, characterized by prominent sandstone ridges 30-90 m above sea level (asl) separated by alluvial flats and gently undulating sandstone or mudstone hills, resulting in the differentiation of two floristic associations of dipterocarp forest: sandstone hill and lowland dipterocarp forests (Fox 1973). The ridges derived from sandstone parent material are dominated by red-yellow podzolic soils with a shallow A horizon consisting of humic, loamy sand with lithosols restricted to the upper slopes (Fox 1973). The alluvial flats, derived from coarse-texture alluvium from the low sandstone and mudstone hills, are characterized by red-yellow podzols (15-30 $\mathrm{m}$ asl). These forest types differ substantially in both species composition and stature (Fox 1973, Nilus 2004). The upper canopy of the alluvial forest type reaches a maximum height of 45-60 m and is dominated by Parashorea tomentella and Shorea johorensis (Dipterocarpaceae) with Eusideroxylon zwageri (Lauraceae) an abundant midcanopy species. The sandstone hill forests are lower in stature, reaching 30$40 \mathrm{~m}$, with an upper canopy dominated by Shorea multiflora, Shorea beccariana, and Dipterocarpus acutangulus (Dipterocarpaceae), which are absent in the alluvial lowland forests. Another noticeable difference is that the sandstone forests show smaller maximum tree girths but higher stem density compared to the alluvial forests (Fox 1973).

As a result of differences in forest structure, the sandstone forest understory receives more direct radiation than that of the alluvial forest (Table 1). Surface soil nutrient availability also differs substantially, with the alluvial soil type having greater concentrations of total $\mathrm{N}$ and $\mathrm{P}$, nitrate, and exchangeable cations (Table 1; Dent 2004). There is a gradient of decreasing nutrient availability from the alluvial to the "kerangas" or heath forest, a third distinct forest type at SFR, with the sandstone soil being intermediate between heath and alluvial soils (Dent 2004). Heath forests are considered nitrogen limited (Proctor et al. 1988), and the gradient of increasing soil nutrient availabilities from heath to alluvial soils would suggest that the sandstone soil will have greater $\mathrm{N}$ limitation than the alluvial soil. Monthly sampling of the matric potential of surface soils over one year failed to detect a consistent difference in soil water availability between alluvial and 
TABLE 2. Species used in survey study.

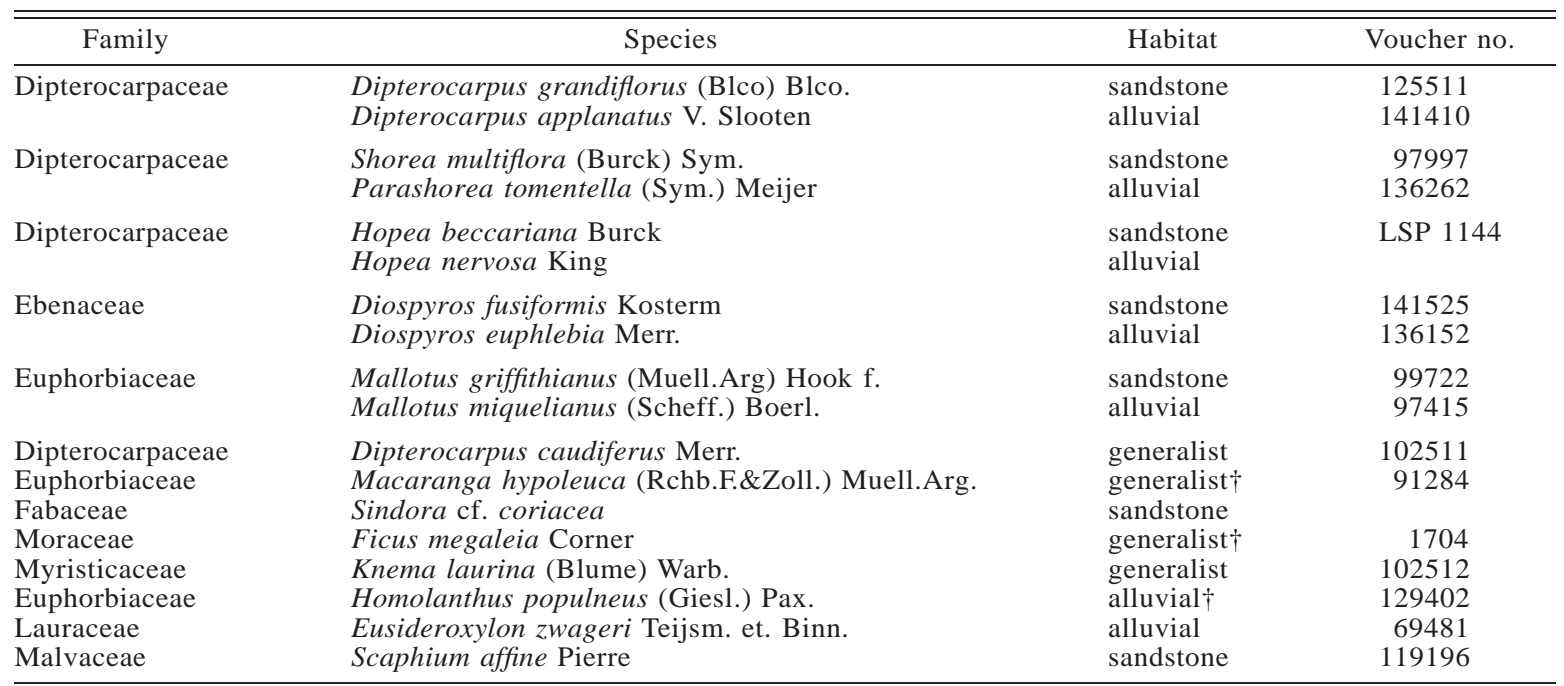

Notes All specimens were identified at the Forest Research Center Herbarium, Sepilok, Sabah.

$\dagger$ Pioneer species.

sandstone soils, although gravimetric soil water content was much lower on the sandstone, and water storage capacity is lower there (Dent 2004). The water table on the alluvial soils is located at $\sim 1.2 \mathrm{~m}$ (Fox 1973), which may be within the rooting zone of saplings occurring there. Freshwater flooding is also a common occurrence on the alluvium (Fox 1973).

\section{Survey data}

To examine patterns of physiological response to soil type, congeneric or confamilial species pairs were selected consisting of one species specialized to the sandstone soil type and the other to the alluvium (Table 2). Five pairs formed phylogenetically independent contrasts in that each species pair shares a common ancestor different from that of any other pair (Felsenstein 1985). Four generalist species were also selected for the study (Table 2). Other common unpaired specialists were selected to provide survey data on a wider range of species. All species used in the study were common, distinctive species classified as edaphic generalists or specialists qualitatively based upon numerous linear transects on each soil type. We searched for "wrongly placed" individuals in the case of specialists, or species that were common on both sandstone and alluvial soil types in the case of generalists. Our classifications correspond closely to data from six 4-ha plots at SFR (four per soil type; Nilus 2004). It should be noted that not all specialists used in the present study are strict specialists in the sense of complete restriction to one soil type, but rather, show strong associations with one soil type over the other. Individuals were sampled along the light gradient (from gap edge to understory) provided by the gaps used in the RTE (see the Reciprocal transplant experiment subsection in Materials and Methods) to obtain a similar range of light environments across species, as many understory species were exposed to high light levels upon gap creation.

\section{Survey species gas exchange}

Using an LI-6400 gas-exchange system (Licor, Lincoln, Nebraska, USA) we made gas-exchange measurements on recent, fully expanded leaves developed in their ambient light environment. All measurements were made before $1200 \mathrm{~h}$ with cuvette conditions maintained at $350 \mathrm{ppm} \mathrm{CO}_{2}$ and $60-80 \%$ relative humidity, and leaf temperatures between 25 and $30^{\circ} \mathrm{C}$. Gas-exchange measurements were made at 13 light levels: 0 , $5,10,15,20,25,50,100,300,500,1000,1500$, and $2000 \mu \mathrm{mol} \cdot \mathrm{m}^{-2} \cdot \mathrm{s}^{-1}$. Gas exchange at a given irradiance was not measured until the leaf was fully induced at that light level, which was determined visually using graphics available in the LI-6400 programming. A single light response curve often took at least one hour to complete due to slow induction response. Twelve saplings per species were selected from the extreme ends of the light gradient for physiological measurements (six high light; six low light). Measurements were made in October-November 2002 at the beginning of a wet spell.

\section{Reciprocal transplant experiment (RTE)}

To evaluate the role of acclimation responses in determining physiological patterns we used a reciprocal transplant design involving five species from the tree family Dipterocarpaceae, an experiment that was part of a collaborative project examining biotic and abiotic factors influencing dipterocarp regeneration (Nilus 2004; British Ecological Society's “Biotic Interactions in Tropical Rain Forest" project). These species in- 
cluded two alluvial specialists, (Hopea nervosa King and Parashorea tomentella (Sym.)Meijer), two sandstone specialists (Hopea beccariana Burck and Shorea multiflora (Burck)Sym.), and one species that does not occur in SFR but is found commonly in other parts of Sabah (Shorea fallax Meijer). We were unable to definitively classify $S$. fallax as either a generalist or an edaphic specialist; therefore it was not considered in this study. Data from six 4-ha plots at SFR indicate that all RTE species show very strong edaphic preferences, although $H$. nervosa had too few individuals to statistically test for habitat association (R. Nilus et al., unpublished manuscript). Parashorea tomentella is a light hardwood and has fairly light-demanding saplings among the dipterocarps (Moad 1992). Hopea beccariana, $H$. nervosa, and $S$. multiflora are all medium hardwood species. The latter two are considered shade tolerant during early stages (Moad 1992, Whitmore and Brown 1996) while little is known about the shade tolerance of $H$. beccariana. Parashorea tomentella, and $H$. nervosa saplings were obtained from the Innoprise (Innoprise Corporation Sdn. Bhd.)-FACE (Forests Absorbing Carbon Dioxide Emissions) Foundation Rainforest Rehabilitation Project Nursery (Danum Valley Field Center, Sabah). They were grown from seed collected from the Ulu Segama Forest Reserve $(150 \mathrm{~km}$ south of SFR) in cylindrical polyethylene bags of 100 $\mathrm{mL}$ containing clay-rich forest soil in shadehouses that provided $\sim 16 \%$ full sunlight. The seeds of $P$. tomentella were collected on 17 September 1996 and H. nervosa on 23 July 1997. Saplings were of uniform age and size within a species. The alluvial saplings were planted on 6-10 March 2000. Wildings of S. multiflora and $H$. beccariana were collected from understory locations (see Table 1 for average understory light availability) on the sandstone soil type at SFR on 11-12 March 2000 , transferred into $840-\mathrm{mL}$ pots of sandstone soil, and transplanted into the planting sites on the same day. Mean heights of saplings at transplantation were $40.2 \mathrm{~cm}$ ( $P$. tomentella), $32.7 \mathrm{~cm}$ (H. nervosa), 38.1 $\mathrm{cm}$ (H. beccariana), and $34.9 \mathrm{~cm}$ (S. multiflora). Saplings were watered regularly for the first four weeks. Dead saplings were replaced four times (4 April, 25 April, 8 June, and 28 July). Mortality during the first four and a half months from initial planting was higher for the sandstone species $(2,6,27$, and $44 \%$ for $H$. nervosa, $P$. tomentella, $H$. beccariana, and $S$. multiflo$r a$, respectively) and was thought to be caused by loss of fine roots during transplantation and heat stress resulting from rapid transfer into gaps (initial mortality rates were much greater in gaps). Therefore in early May 2000, three temporary nurseries were created in the forest in shaded locations adjacent to the planting sites. Saplings were again initially transferred to the 840-mL pots of soil but kept in the temporary nurseries prior to transplantation. After two weeks saplings were transferred to the edges of the planting sites and used to replace dead plants on 8 June and 28 July 2000.
Saplings that had acclimated to the new growing conditions prior to transplantation (June and July replacement plantings) showed greatly reduced initial mortality rates. The time courses of mortality rate following this improved planting method show no substantial differences between the first census interval (July to November 2000) and the interval from 1 November 2000 to March 2002 for the sandstone species, and increase over time for the alluvial species (Nilus 2004). To minimize potential differences arising from seed sources and pretransplant growth conditions, data were collected a year and a half after transplantation, by which time plants in the high-light treatments had grown 510 times larger in height, diameter, and leaf number.

Five sites were established on the sandstone soil type and five on the alluvium, each consisting of paired understory and gap plots. Small trees and overhanging branches were removed where necessary to enlarge natural gaps to $400-600 \mathrm{~m}^{2}$. All previous regrowth in the gap was also cleared. Weeding was conducted regularly in the gaps to minimize spatial and temporal variation in light environment. Understory plots were located $\sim 50 \mathrm{~m}$ from the gaps on sites of similar topography and elevation. Within each plot, 15 blocks of 10 saplings ( 2 per study species plus 2 Shorea fallax, a species not considered in this study for reasons outlined above) were arranged in a gridlike pattern within the plot, with 0.75-m spacing between saplings. Saplings were sorted into 30 height categories with each plot receiving one sapling per size category per species to equalize sapling size across treatments. Saplings were then allocated randomly to blocks and planting position within blocks. To minimize root damage, a small volume of soil was left surrounding the root system. One sapling per species per block received fertilization consisting of $12 \mathrm{~g}$ of Agroblen (Scotts PBG Malaysia Sdn. Bhd., Selangor, Malaysia) six-month slow-release fertilizer (16:8: 9:3, N:P:K:Mg + trace elements) applied in a shallow trench $3 \mathrm{~cm}$ from the sapling base every six months. The initial treatment was implemented following final seedling replacements.

\section{RTE gas exchange}

Photosynthetic light response measurements were made as described in the Survey species gas exchange subsection in Materials and Methods. Three sites per soil type were selected for measurements and one individual per species and treatment randomly selected at each site for light response measurements. Three additional individuals per treatment and species (one per plot) were randomly selected for measurement of dark respiration $\left(R_{\mathrm{d}}\right)$ and photosynthetic capacity $\left(A_{\max }\right)$ to increase sample sizes for these parameters. In the understory plots, we measured leaves formed in the treatment to avoid potential leaf-level physiological differences among saplings due to prior growing conditions. Measurements were made in October and No- 
TABLE 3. Comparisons of physiological parameters (mean \pm SE) of sandstone and alluvial specialists, and each soil-type specialist vs. generalists, with $t$ and $P$ statistics.

\begin{tabular}{lccc}
\hline \hline Soil type & $A_{\max }\left(\mu \mathrm{mol} \cdot \mathrm{m}^{-2} \cdot \mathrm{s}^{-1}\right)$ & $R_{\mathrm{d}}\left(\mu \mathrm{mol} \cdot \mathrm{m}^{-2} \cdot \mathrm{s}^{-1}\right)$ & $g_{\mathrm{s}}\left(\mathrm{mmol} \cdot \mathrm{m}^{-2} \cdot \mathrm{s}^{-1}\right)$ \\
\hline Sandstone & $4.03 \pm 0.26$ & $0.548 \pm 0.053$ & $0.067 \pm 0.006$ \\
Alluvial & $6.46 \pm 0.69$ & $0.568 \pm 0.073$ & $0.143 \pm 0.030$ \\
$t$ & $\mathbf{4 . 8 1}(<\mathbf{0 . 0 0 0 1})$ & $1.20(0.2343)$ & $\mathbf{4 . 0 4}(\mathbf{0 . 0 0 0 2})$ \\
Sandstone & $4.34 \pm 0.33$ & $0.505 \pm 0.056$ & $0.052 \pm 0.006$ \\
Generalist & $6.52 \pm 0.79$ & $0.585 \pm 0.069$ & $0.146 \pm 0.031$ \\
$t$ & $\mathbf{3 . 6 7}(\mathbf{0 . 0 0 0 6})$ & $0.43(0.6732)$ & $\mathbf{3 . 2 8}(\mathbf{0 . 0 0 1 9})$ \\
Alluvial & $6.46 \pm 0.69$ & $0.568 \pm 0.073$ & $0.165 \pm 0.024$ \\
Generalist & $8.61 \pm 1.18$ & $0.557 \pm 0.069$ & $0.206 \pm 0.029$ \\
$t$ & $-1.74(0.0891)$ & $0.95(0.3460)$ & $-1.07(0.2917)$ \\
A-S & $1.82(0.1426)$ & $-0.13(0.9041)$ & $\mathbf{3 . 3 6}(\mathbf{0 . 0 2 8 2})$ \\
\hline
\end{tabular}

Notes Abbreviations are: WUE, water-use efficiency; PNUE, photosynthetic nitrogen-use efficiency. $P$ values are in parentheses, with $P$ values $<0.05$ in boldface. The final row contains $t$ values and significance values for paired $t$ test comparisons of physiological parameters of sister species pairs of alluvial and sandstone specialists (A-S).

vember 2001 at the beginning of a wet spell after the plants had been in treatment for one and a half years.

\section{Leaf nutrient and stable carbon isotope analysis}

Gas-exchange leaves were harvested, measured for fresh leaf area, dried at $60^{\circ} \mathrm{C}$, and weighed. Leaf tissue, excluding major veins, was finely ground using a mortar and pestle. Survey species samples were digested using the sulfuric acid-hydrogen peroxide digest procedure. The digest was analyzed for total nitrogen using the phenol blue (Berthelot) reaction in a continuousflow analyzer (Technicon Auto-analyzer II, Technicon Scandinavia, Stockholm, Sweden) (Schuman et al. 1973). Analyses were conducted in the Soil Science Laboratory, Faculty of Forestry, University of Toronto, Ontario, Canada. Leaf $\mathrm{N}$ was measured for the gap RTE samples using an ECS $4010 \mathrm{CHN}$ analyzer (Costech International, Milan, Italy). We used a citrus leaf standard of known nutrient concentration (National Bureau of Standards 1572) and duplicate samples of our species (as cross-references) to ensure accuracy and comparability of methods. Stable carbon isotope ratios $\left(\delta^{13} \mathrm{C}\right)$ were measured for leaf samples of the gap RTE saplings and the three highest light replicates of survey species pairs and generalists to estimate integrated WUE. Stomatal limitation is expected to lead to greater proportional uptake of the heavier ${ }^{13} \mathrm{C}$ isotope caused by reduced discrimination between isotopes (Farquhar et al. 1982). Consequently, isotopic signatures provide an indication of water-use efficiency integrated over the leaf lifetime (Farquhar et al. 1989). Analyses were performed at the Stable Isotope Facility, University of California, Davis, California, USA using a Hydra 2020 stable isotope analyzer combined with an ANCA GSL (PDZ Europa, Cheshire, UK). Understory leaf tissue was not collected due to limited leaf area of these individuals. Removal of leaf tissue would have impacted concurrent studies of leaf demography and herbivory and may have influenced sapling growth rates in low-light treatments, given the very limited number of leaves on most understory saplings.

\section{Characterization of sapling environment}

Individual sapling light environments were measured using hemispherical photographs taken directly above the crown of each sapling with a Nikon Coolpix 900 and a Nikon FC-E8 fisheye converter (Nikon, Tokyo, Japan). Photographs were analyzed using the program Winscanopy 2001 (Regent Instruments, Québec, Canada). Above-canopy direct radiation is a function of the latitude and longitude and the defined growing season while above-canopy diffuse radiation is taken as $15 \%$ of the direct radiation. Individual sapling light environment was used to determine the three individuals receiving the highest light levels for the survey data analysis. Additionally, five photographs were taken at a fixed height $(1 \mathrm{~m})$ within each gap and understory plot to estimate differences in light availability between soil types and light treatments. Photographs were generally taken on overcast days or early in the morning. Differences in light availability were tested using ANOVA (PROC GLM, SAS Institute, Cary, North Carolina, USA), with soil type and light treatment as independent variables and daily total, direct, and indirect radiation as dependent variables. The results for the RTE plots are summarized in Table 1.

Samples to assess soil nutrient status were taken at $0-5 \mathrm{~cm}$ and $15-20 \mathrm{~cm}$ depths at three locations within each RTE gap and understory plot in August 2001. Potassium chloride solution (6\% v/v) was used to extract nitrate and ammonium from fresh and air-dried soil samples, and acetic acid solution $(2.5 \% \mathrm{v} / \mathrm{v})$ was used to extract phosphate. For the determination of total $\mathrm{N}$ and $\mathrm{P}, 0.10-0.20 \mathrm{~g}$ of ground, oven-dried material was digested using the sulfuric acid-hydrogen peroxide digest procedure; concentrations of total $\mathrm{P}, \mathrm{PO}_{4}, \mathrm{NO}_{3}$, and $\mathrm{NH}_{4}$ were assessed using a flow-injection autoanalyzer (Tecator FIA Star 5010 Analyzer, Foss Tecator, Hoeganaes, Sweden), and total N concentrations were analyzed using a continuous-flow analyzer (Technicon Auto-analyzer II). 
TABLE 3. Extended.

\begin{tabular}{cccc}
\hline \hline$C_{\mathrm{i}}(\mu \mathrm{mol} / \mathrm{mol})$ & WUE $(\mathbf{m m o l} / \mathrm{mol})$ & $\delta^{13} \mathrm{C}(\%)$ & PNUE $\left(A_{\text {area }} / \mathrm{N}_{\text {area }}\right)$ \\
\hline $243 \pm 6$ & $3.750 \pm 0.240$ & $-32.68 \pm 0.26$ & $1.592 \pm 0.21$ \\
$271 \pm 6$ & $2.927 \pm 0.189$ & $-34.31 \pm 0.23$ & $2.233 \pm 0.10$ \\
$\mathbf{3 . 5 8}(\mathbf{0 . 0 0 0 7 )}$ & $-\mathbf{3 . 0 2}(\mathbf{0 . 0 0 4 2})$ & $-\mathbf{4 . 7 3}(<\mathbf{0 . 0 0 0 1})$ & $\mathbf{2 . 8 6}(\mathbf{0 . 0 0 6})$ \\
$243 \pm 6$ & $3.75 \pm 0.27$ & $-32.68 \pm 0.26$ & $1.592 \pm 0.21$ \\
$270 \pm 7$ & $2.87 \pm 0.25$ & $-33.79 \pm 0.26$ & $1.800 \pm 0.21$ \\
$\mathbf{2 . 9 6 ( 0 . 0 0 5 3 )}$ & $-\mathbf{2 . 5 2}(\mathbf{0 . 0 1 6 1 )}$ & $-\mathbf{2 . 1 1}(\mathbf{0 . 0 4 9 5 )}$ & $0.88(0.3951)$ \\
$271 \pm 6$ & $2.858 \pm 0.172$ & $-34.31 \pm 0.23$ & $2.233 \pm 0.10$ \\
$278 \pm 7$ & $2.835 \pm 0.204$ & $-34.12 \pm 0.60$ & $1.984 \pm 0.24$ \\
$-0.74(0.4671)$ & $0.09(0.9308)$ & $-0.32(0.7486)$ & $0.77(0.4467)$ \\
$\mathbf{3 . 7 9}(\mathbf{0 . 0 1 9 2 )}$ & $-\mathbf{5 . 0 9}(\mathbf{0 . 0 0 7 0 )}$ & $-\mathbf{6 . 6 5}(\mathbf{0 . 0 0 2 7})$ & $2.19(0.0932)$ \\
\hline
\end{tabular}

\section{Light response parameterization and analysis}

The response of photosynthetic assimilation to photon flux density (PFD) was fitted to a nonrectangular hyperbola (PROC NLIN, SAS Version 8.1, SAS Institute, Cary, North Carolina, USA) (Leverenz 1988, Ogren and Evans 1993):

$$
P=R_{\mathrm{d}}+\frac{\phi I+A_{\max }-\sqrt{\left[\left(\phi I+A_{\max }\right)^{2}-4 \Theta \phi L A_{\max }\right]}}{2 \Theta}
$$

where $P$ is photosynthetic rate, $R_{\mathrm{d}}$ is leaf-level dark respiration, $\phi$ is apparent quantum yield of photosynthesis, $I$ is the photosynthetic photon flux density, $A_{\max }$

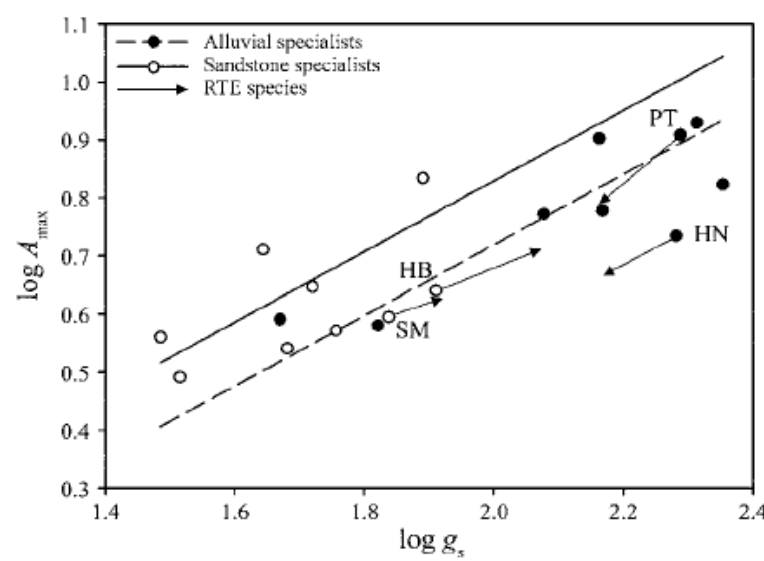

FIG. 1. Standardized major axis (SMA) relationship between $\log A_{\max }$ (photosynthetic capacity, $\mu \mathrm{mol} \mathrm{m}^{-2} \cdot \mathrm{s}^{-1}$ ) and $\log g_{\mathrm{s}}$ (stomatal conductance, $\mathrm{mmol} \cdot \mathrm{m}^{-2} \cdot \mathrm{s}^{-1}$ ) for species specialized to sandstone and alluvial soil types. Arrows indicate the acclimatory shift of the sandstone and alluvial specialists used in the reciprocal transplant experiment when grown on their native and nonnative soils. Species' initials are adjacent to the mean value on their native soil type and are as follows: HB, Hopea beccariana; SM, Shorea multiflora; HN, Hopea nervosa; PT, Parashorea tomentella. Common slopes were fitted for each soil type: sandstone, $0.825(95 \% \mathrm{CI}=[0.378$, $1.801])$; alluvial, $0.548(95 \% \mathrm{CI}=[0.335,0.897])$. Individual slopes did not differ $(P=0.315)$, with a common slope of $0.608(95 \% \mathrm{CI}=[0.409,0.900])$, at a given $g_{5} ;$ however, sandstone species achieved greater $A_{\max }$ than alluvial species $(P=0.022)$. is the asymptotic light saturated photosynthetic rate, and $\Theta$ is the convexity of the curve.

Maximum stomatal conductance to water $\left(g_{\mathrm{s}}\right)$ corresponding to $A_{\max }$ was used to characterize stomatal response across species, treatments, and soil types. Instantaneous water-use efficiency (WUE) was calculated as follows:

$$
\mathrm{WUE}=A_{\max } / E
$$

where $A_{\max }$ is photosynthetic capacity in $\mu \mathrm{mol} \cdot \mathrm{m}^{-2} \cdot \mathrm{s}^{-1}$ and $E$ is transpiration in $\mathrm{mol} \cdot \mathrm{m}^{-2} \cdot \mathrm{s}^{-1}$, thus providing a value indicating $\mu$ moles of carbon gained per mole of water lost. Photosynthetic nitrogen-use efficiency (PNUE) was calculated as

$$
\text { PNUE }=A_{\max } / \mathrm{N}_{\text {area }}
$$

where $\mathrm{N}$ is in $\mathrm{g} / \mathrm{m}^{2}$, thus quantifying $\mu$ moles of carbon gained per gram of nitrogen investment.

To test for differences among soil types, treatments, and species in the RTE, parameter values were subjected to a nested analysis of variance (ANOVA) (PROC GLM, SAS). Dependent variables included $A_{\max }, R_{\mathrm{d}}, g_{\mathrm{s}}$, internal $\mathrm{CO}_{2}\left(C_{\mathrm{i}}\right)$, instantaneous WUE, $\delta^{13} \mathrm{C}$ (integrated WUE), and PNUE. All dependent variables were tested for normality prior to analysis using Kolmogorov-Smirnov test for goodness of fit. Independent variables included species, soil type, plot nested within soil type, light nested within plot and soil type, and fertilization nested within light, plot, and soil type and all interactions. Separate ANOVAs were conducted for each species to examine treatment effects on individual species. Pairwise differences reported in the figures are from this analysis except Fig. 4, where comparisons are across species. A post hoc Tukey-Kramer test was used to test for pairwise differences between treatments.

To examine group differences in physiological parameters among sandstone specialists, alluvial specialists, and soil type generalists, $t$ tests were performed on the survey data. Paired $t$ tests were employed to examine physiological differences between sister species pairs to correct for the influence of phylogeny. Additionally, phylogenetically independent contrasts 
TABLE 4. Nested ANOVA for the effects of species, soil, and light nested with soil and all possible interactions.

\begin{tabular}{|c|c|c|c|c|c|c|c|}
\hline \multirow[b]{2}{*}{ Source } & \multirow[b]{2}{*}{ df } & \multicolumn{2}{|c|}{$A_{\max }$} & \multicolumn{2}{|c|}{$R_{\mathrm{d}}$} & \multicolumn{2}{|c|}{$g_{5}$} \\
\hline & & $F$ & $P$ & $F$ & $P$ & $F$ & $P$ \\
\hline Species & 3 & 29.5 & $<0.0001$ & 10.63 & $<0.0001$ & 13.55 & $<0.0001$ \\
\hline Soil & 1 & 16.2 & $<0.0001$ & 19.94 & $<0.0001$ & 14.85 & 0.0002 \\
\hline Species $\times$ soil & 3 & 1.33 & 0.2664 & 1.58 & 0.1964 & 1.55 & 0.2035 \\
\hline Light (soil) & 2 & 47.9 & $<0.0001$ & 50.55 & $<0.0001$ & 16.76 & $<0.0001$ \\
\hline Species $\times$ light (soil) & 6 & 2.3 & 0.0029 & 1.89 & 0.0206 & 1.24 & 0.2344 \\
\hline
\end{tabular}

Notes Plot and fertilization effects were nonsignificant in all cases and were thus excluded. Statistically significant results $(P<0.05)$ are in boldface. Model and error degrees of freedom for $A_{\max }, R_{\mathrm{d}}, g_{\mathrm{s}}, C_{\mathrm{i}}$, and WUE (water-use efficiency) were 15 and 177, respectively $(n=12)$. Model and error degrees of freedom for $\delta^{13} \mathrm{C}$ and PNUE (photosynthetic nitrogen-use efficiency) were 7 and 56, respectively $(n=4)$.

(Felsenstein 1985) were calculated as the difference between sister species trait values using ACAP 2 (D. D. Ackerley, unpublished program). The results of this analysis agreed quantitatively with all other analyses; therefore these results are not presented. We were interested in testing for potential differences in the $A_{\max }-g_{5}, A_{\max }-R_{\mathrm{d}}$ and $A_{\max }-\% \mathrm{~N}$ relationships for species associated with each soil type. Standardized major axis (SMA) slope-fitting techniques were considered appropriate, as there was error associated with both $X$ and $Y$ variables. Differences in the SMA slopes for sandstone and alluvial soil types were tested following Warton and Weber (2002) using standardized major axis tests and routines ([S] MATR, Falster et al. 2003). Shifts in bivariate relationship elevation between the two groups were tested using an ANCOVA-like procedure (ANOVA following transformation of the data

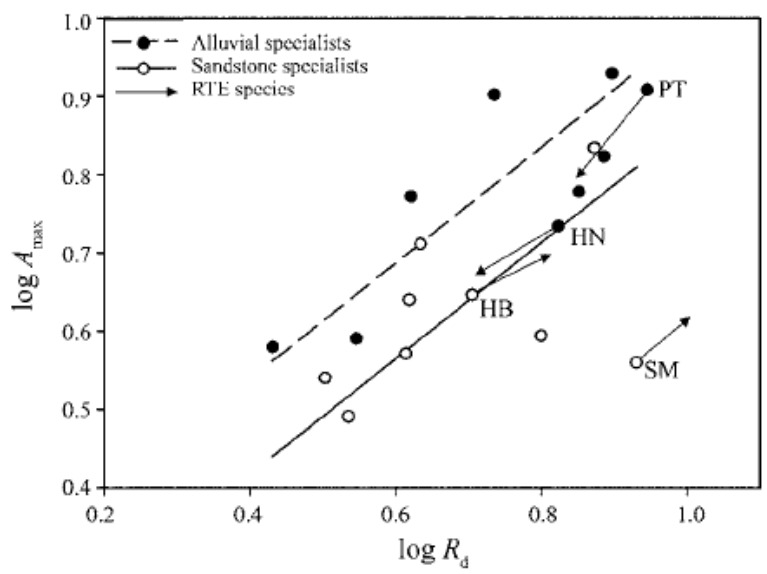

FIG. 2. SMA relationship between $\log A_{\max }$ (photosynthetic capacity, $\mu \mathrm{mol} \mathrm{m}^{-2} \cdot \mathrm{s}^{-1}$ ) and $\log R_{\mathrm{d}}$ (dark respiration rates, $\mu \mathrm{mol} \cdot \mathrm{m}^{-2} \cdot \mathrm{s}^{-1}$ ) for sandstone and alluvial specialists. $R_{\mathrm{d}}$ values were multiplied by 10 to avoid negative log values. Arrows indicate the acclimatory shift of the sandstone and alluvial specialists used in the reciprocal transplant experiment when grown on their native and nonnative soils. Species acronyms are as in Fig. 1. Common slopes fitted to each soil type are as follows: sandstone, $0.708(95 \% \mathrm{CI}=[0.314$, $1.597])$; alluvial, $0.756(95 \% \mathrm{CI}=[0.416,1.374])$. Individual slopes did not differ $(P=0.880)$, with a common slope of $0.740(95 \% \mathrm{CI}=[0.482,1.138])$; at a given $R_{\mathrm{d}}$, however, sandstone species achieved a lower $A_{\max }(P=0.030)$. to remove the correlation between $X$ and $Y$ variables) using (S) MATR (Falster et al. 2003). In all cases, $A_{\max }$ was the $Y$ variable, $g_{s}, R_{\mathrm{d}}$, or $\% \mathrm{~N}$ the $X$ variable, and soil type the grouping variable. Area-based $\mathrm{N}$ values were not used as the two Diospyros species and Eusideroxlyon zwageri had extremely low specific leaf area (SLA, $\mathrm{cm}^{2} / \mathrm{g}$ of leaf tissue) values, and their $\mathrm{N}_{\text {area }}$ values were obvious outliers. When these three species were excluded, the $A_{\max } \% \mathrm{~N}$ and $A_{\max }-\mathrm{N}_{\text {area }}$ relationships showed the same shifts between sandstone and alluvial species. All data were log transformed prior to analysis. Mean physiological parameters for the three individuals of each species growing in the highest light environments were used, as certain species (i.e., pioneers) only occurred in high light. Species' means were used as we were interested in cross-species comparisons.

\section{RESULTS}

\section{Survey data}

Alluvial specialists and edaphic generalists had higher photosynthetic rates $\left(A_{\max }\right)$, stomatal conductances to water $\left(g_{\mathrm{s}}\right)$, and internal $\mathrm{CO}_{2}$ concentrations $\left(C_{\mathrm{i}}\right.$, $\mu \mathrm{mol} / \mathrm{mol}$ ) than the sandstone specialists (Table 3 ). Mean dark respiration rates $\left(R_{\mathrm{d}}\right)$ did not differ among these groups (Table 3 ). Sandstone specialists had both higher instantaneous WUE and integrated water-use efficiency $\left(\delta^{13} \mathrm{C}\right)$ than either alluvial specialists or generalist species (Table 3). Mean photosynthetic nitrogenuse efficiency (PNUE) however, was higher in the alluvial specialists and generalists than in the sandstone specialists (Table 3). Alluvial specialists and edaphic generalists did not differ in any of the measured parameters. Paired $t$ tests between sister taxa resulted in similar findings, with alluvial specialists having higher $g_{s}, C_{i}$, and PNUE than sandstone specialists (Table 3). $A_{\max }$ and $R_{\mathrm{d}}$ did not differ between pairs (Table 3 ). $\delta^{13} \mathrm{C}$ was greater for the sandstone specialists, as was instantaneous WUE (Table 3).

Similar overall patterns were apparent in the $A_{\max }-$ $g_{5}, A_{\max }-R_{\mathrm{d}}$, and $A_{\max }-\% \mathrm{~N}$ relationships between edaphic specialists. In all cases, slopes of these bivariate relationships were homogeneous between the two groups, but the elevation of the slopes differed. Sand- 
TABLE 4. Extended.

\begin{tabular}{|c|c|c|c|c|c|c|c|}
\hline \multicolumn{2}{|c|}{$C_{\mathrm{i}}$} & \multicolumn{2}{|c|}{ WUE } & \multicolumn{2}{|c|}{$\overline{8} \delta^{13} \mathrm{C}$} & \multicolumn{2}{|c|}{ PNUE } \\
\hline$F$ & $P$ & $F$ & $P$ & $F$ & $P$ & $F$ & $P$ \\
\hline 2.34 & 0.0802 & 4.43 & 0.0051 & 6.79 & 0.0018 & 20.51 & $<0.0001$ \\
\hline 1.09 & 0.2994 & 8.84 & 0.0034 & 0.88 & 0.3581 & 1.84 & 0.1791 \\
\hline 1.17 & 0.3277 & 4.07 & 0.0082 & 0.73 & 0.5414 & 0.57 & 0.6818 \\
\hline 10.34 & 0.0001 & 5.63 & $<0.0001$ & & & & \\
\hline 1.03 & 0.4122 & 1.81 & 0.0291 & & & & \\
\hline
\end{tabular}

stone specialists achieved higher $A_{\max }$ per unit $g_{5}$ than alluvial specialists (Fig. 1). Sandstone specialists exhibited lower $A_{\max }$ per unit $R_{\mathrm{d}}$ (Fig. 2) and lower $A_{\max }$ at a given $\% \mathrm{~N}$ than alluvial specialists (Fig. 3). For mean parameter values on a species basis, refer to Appendix A.

\section{Reciprocal transplant experiment}

Fertilization had no effect on any measured physiological parameters or their interactions across species and treatments. There was no evidence of elevated leaf nitrogen in the fertilized plants. Subsequent analyses therefore pool the fertilization treatment.

Species with a habitat preference for the alluvial soil type displayed higher $A_{\max }$ than sandstone specialists (Table 4). The alluvial specialist $P$. tomentella exhibited the highest $A_{\max }$ and sandstone specialist $S$. multiflora the lowest (Fig. 4A). All species showed greater photosynthetic acclimation to light environment when grown on the alluvial soil type (Fig. 4A, Table 4). Despite greater light availability in the sandstone under-

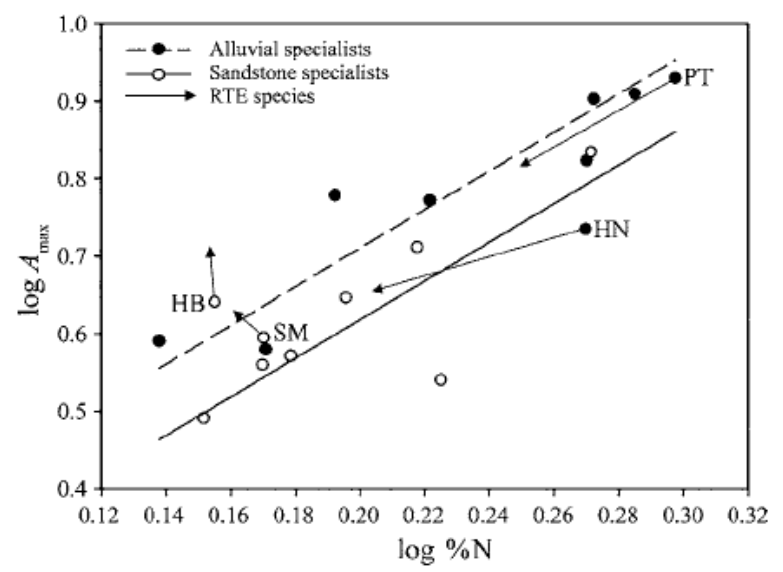

FIG. 3. SMA relationship between $\log A_{\max }$ (photosynthetic capacity, $\mu \mathrm{mol} \mathrm{m}^{-2} \cdot \mathrm{s}^{-1}$ ) and $\log \% \mathrm{~N}$ (leaf nitrogen content) for sandstone and alluvial specialists. Arrows indicate the acclimatory shift of the sandstone and alluvial specialists used in the reciprocal transplant experiment when grown on their native and nonnative soils. Species acronyms are as in Fig. 1. Common slopes fitted to each soil type are as follows: sandstone, $2.93(95 \% \mathrm{CI}=[1.61,5.32])$; alluvial, $2.32(95 \%$ $\mathrm{CI}=[1.56,3.47])$. Individual slopes did not differ $(P=$ $0.473)$, with a common slope of $2.486(95 \% \mathrm{CI}=[1.838$, $3.357]$ ); at a given $\mathrm{N}$ content, however, sandstone species achieved lower $A_{\max }$ than alluvial species $(P=0.013)$. story, there was a pattern of lower $A_{\max }$ there than in the alluvial understory (Fig. 4A).

Dark respiration rates were consistently higher on the alluvial soil type (Table 4), as would be expected given the photosynthetic response to soil type. Patterns of $R_{\mathrm{d}}$ across species, however, do not track those of $A_{\max }$, as would be expected given the close relationships among these factors. In the gaps, sandstone specialists achieved the lowest $A_{\max }$ (Fig. 4A) but their $R_{\mathrm{d}}$ were equivalent to or greater than those of the alluvial species capable of higher $A_{\max }$ (Fig. 4B). For example, on the sandstone soil type, sandstone specialists $H$. beccariana and $S$. multiflora show $R_{\mathrm{d}}$ equivalent to or greater than the alluvial specialist $P$. tomentella, while the $A_{\max }$ of $P$. tomentella was nearly double that of either sandstone specialist species (Fig. 4A, B).

Stomatal conductance was significantly higher for the alluvial specialists than for the sandstone specialists, with the largest difference observed in the gaps (Fig. 4C; Table 4). This difference was proportionally greater in most cases than would be expected if $A_{\max }$ were tracking $g_{5}$. For all species, $g_{5}$ was lower on the sandstone than the alluvial soil type and greater in the gaps than in the understory (Fig. 4C; Table 4).

Internal $\mathrm{CO}_{2}$ concentrations were generally greater in alluvial specialists than in the sandstone specialists (Table 4). Within-species $C_{\mathrm{i}}$ changed very little with treatment; however, there was a significant trend toward higher $C_{\mathrm{i}}$ in the understory than in the gap plants, which was due to the extremely low photosynthetic rates and consequently low $\mathrm{CO}_{2}$ drawdown in saplings growing in the understory (Table 4).

Sandstone specialists, in particular S. multiflora, tended to have greater WUE than alluvial specialists, although this trend was not significant for RTE species (Table 4). WUE was slightly higher on the sandstone, primarily due to a single significant increase in WUE of $P$. tomentella in the sandstone understory. $\delta^{13} \mathrm{C}$ followed a similar pattern, with the sandstone specialist $S$. multiflora having the least negative $\delta^{13} \mathrm{C}$ values, indicating greater long-term WUE, and the alluvial specialists showing the most negative $\delta^{13} \mathrm{C}$ values (Fig. 5A; Table 4). Sandstone specialists tended to have lower PNUE than alluvial specialists (Table 4). Parashorea tomentella had the greatest PNUE while $S$. multiflora had the lowest (Fig. 5B). 


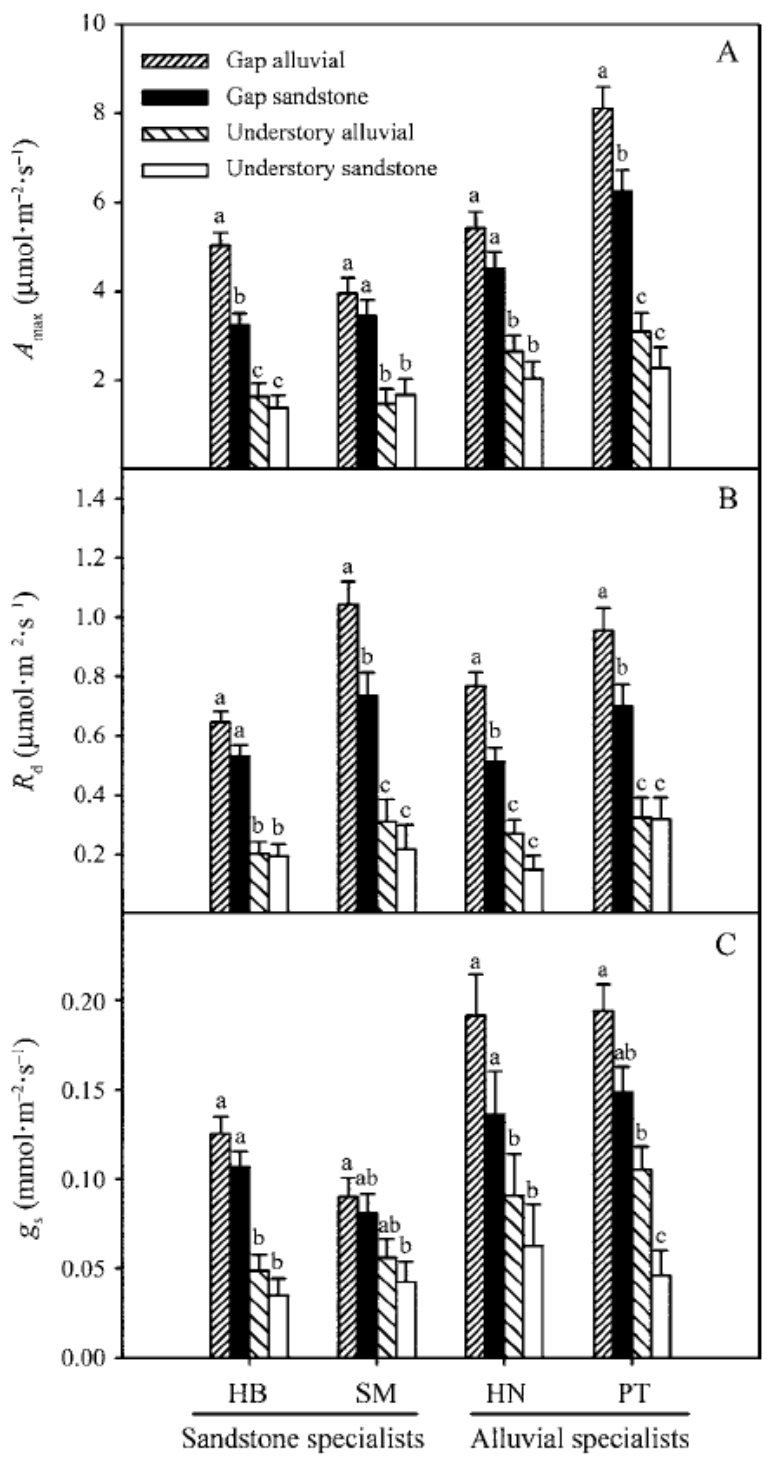

FIG. 4. Light treatment and soil type effects (mean + SE) on (A) photosynthetic capacity, (B) dark respiration, and (C) stomatal conductance for the reciprocal transplant experiment. Species acronyms are as in Fig. 1. Pairwise differences are within species only.

\section{Acclimatory shifts}

Shifts in the $A_{\max }-g_{5}, A_{\max }-R_{\mathrm{d}}$, and $A_{\max }-\% \mathrm{~N}$ relationships when transplanted onto their nonnative soil type were superimposed on Figs. 1-3 for the RTE species. The alluvial specialists ( $P$. tomentella and $H$. nerv$o s a$ ) reduced both $A_{\max }$ and $g_{5}$ when grown on the sandstone soil type. Stomatal conductance was reduced at a slightly greater rate, causing greater divergence of both species from the sandstone regression line (Fig. 1). The two sandstone specialists shifted only slightly in their $A_{\max }$ and $g_{5}$ values when grown on the alluvial soil type. Both $H$. beccariana and $S$. multiflora fell slightly below the alluvial regression. Acclimatory shifts did not alter intrinsic WUE substantially for ei- ther species (Fig. 1). Sandstone specialists increased $R_{\mathrm{d}}$ per unit $A_{\max }$ when grown on the alluvial soil, while alluvial specialists showed fairly proportional reductions in $R_{\mathrm{d}}$ and $A_{\max }$ when transplanted onto the sandstone (Fig. 2). H. beccariana achieved high $A_{\max }$ per $\% \mathrm{~N}$ in comparison with other sandstone species. Both sandstone specialists increased $A_{\max }$ per $\% \mathrm{~N}$ when grown on the alluvium, thus shifting their values above the alluvial regression line (Fig. 3). The sandstone values for the alluvial specialists still fell within the range of the alluvial regression (Fig. 3). H. nervosa increased its PNUE when grown on the sandstone soil type.

\section{Discussion}

The resource-use efficiency (RUE) hypothesis asserts that species occurring in resource-poor environments have been selected for traits that improve the resource-use efficiency of the resources in limitation in that environment. This efficiency of resource use provides species occurring in resource-poor environments a competitive advantage over species not naturally occurring there, particularly if resource availability fluctuates to include periods of extreme shortage. However, for the RUE hypothesis to account for species edaphic associations there must also be some limit to acclimation: species occurring in the more resource-rich environment must not be capable of acclimation to change their patterns of RUE to match those of species characteristic of the resource-poor environment. Additionally, for resource-use efficiency to explain habitat specialization, generalist species should be less efficient in the use of limiting resources than specialist species (Futuyma and Moreno 1988, Caley and Munday 2003). The present study uses phylogenetically independent comparisons of survey data and experimental reciprocal transplantation to test whether tree species specialized to the drier, sandstone-derived ridges have greater physiological resource-use efficiency in terms of either water or nitrogen, in comparison with specialists from the alluvial valleys and generalist species. Additionally, we test whether tradeoffs exist in the RUE of these two potentially limiting resources on the sandstone ridges. Our results indicate that sandstone specialists exhibit a conservative wateruse strategy not evident in either alluvial specialists or generalist species. Enhanced water-use efficiency came at the cost of higher metabolic rates and reduced photosynthetic nitrogen-use efficiency than either alluvial specialists or generalists, suggesting that a trade-off exists between physiological water and nutrient use in the sandstone specialists. Finally, we address the issue of acclimatory response with a reciprocal transplant experiment. Alluvial specialists were not capable of acclimation to behave as sandstone specialists when grown on the sandstone ridges. These results indicate that resource-use efficiency in the form of a conservative water-use strategy is important in maintaining sandstone specialization at SFR. 


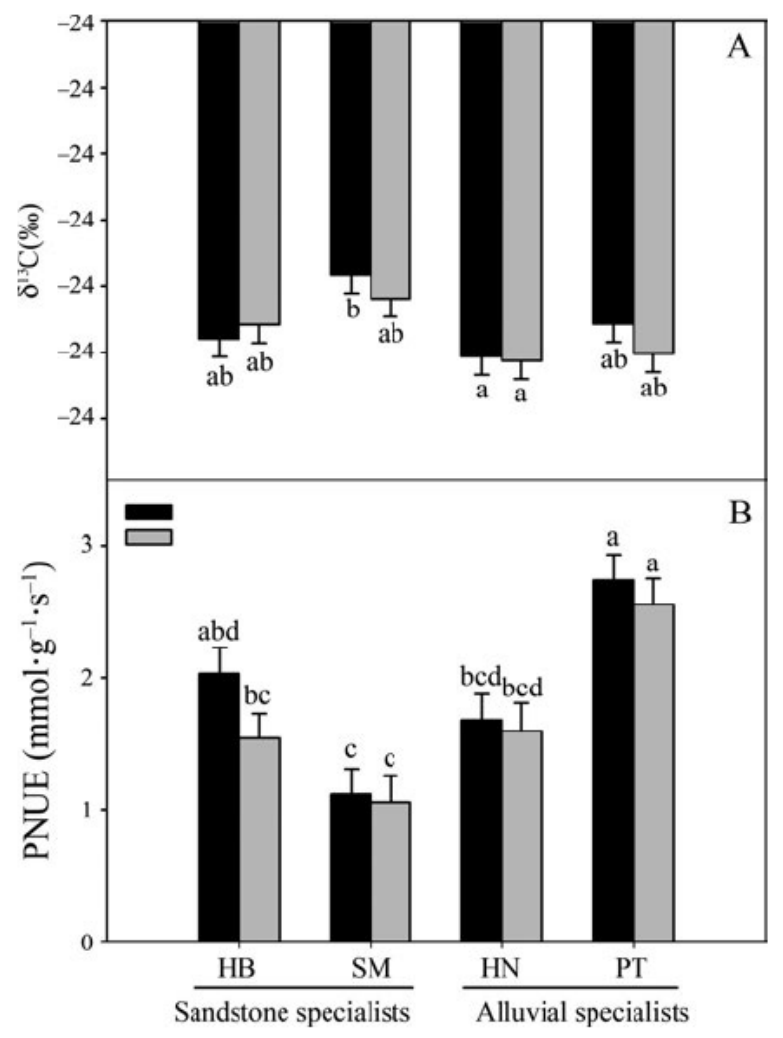

FIG. 5. Soil type effects (mean $+\mathrm{SE}$ ) on (A) integrated water-use efficiency and (B) photosynthetic nitrogen-use efficiency (PNUE) for the reciprocal transplant experiment. Species acronyms are as in Fig. 1. Pairwise differences are across species.

\section{Water-use efficiency}

There were pronounced differences in gas-exchange patterns driven by a conservative water-use strategy on the part of the sandstone specialists (lower $g_{5}$ per unit $A_{\max }$ resulting in greater WUE). This strategy, however, incurred proportionally higher respiratory $\left(R_{\mathrm{d}}\right)$ costs in comparison to those exhibited by the alluvial specialists or the generalist species. Instantaneous WUE of the sandstone specialists was $28 \%$ and $24 \%$ greater than alluvial specialists and generalist species, respectively, and a similar pattern held for integrated WUE $\left(\delta^{13} \mathrm{C}\right.$, Table 4). This pattern was driven by changes in stomatal conductance $\left(g_{5}\right)$, which was lower at a given photosynthetic capacity $\left(A_{\max }\right)$ for sandstone specialists (Fig. 1). Reduced $g_{5}$ resulted in the sandstone specialists having lower internal $\mathrm{CO}_{2}$ concentrations $\left(C_{\mathrm{i}}\right.$, Table $3)$. This leads to the question of how they were able to maintain similar photosynthetic rates given lower $C_{\mathrm{i}}$. If $C_{\mathrm{i}}$ is reduced, photosynthetic enzyme concentrations must increase in either quantity or efficiency to maintain a given photosynthetic rate. Increased photosynthetic enzyme concentrations would lead to higher $R_{\mathrm{d}}$, given that a large fraction of $R_{\mathrm{d}}$ is thought to be explained by protein turnover (Lambers et al. 1983, Ryan 1995), thus accounting for the observed shift in the
$A_{\max }-R_{\mathrm{d}}$ relationship. Our results are similar to those of Wright et al. (2001), who demonstrated that Australian perennial species native to more xeric sites exhibited lower $g_{\mathrm{s}}$ and higher $R_{\mathrm{d}}$ per unit $A_{\text {area }}$ than species from more mesic sites. The sandstone specialists' conservative water-use strategy was not evident in alluvial specialists or generalist species. Alluvial specialists were also not capable of sufficient plasticity to behave as sandstone specialists when grown on the sandstone soil type, as demonstrated with the RTE. These findings thus provide support for the RUE hypothesis in explaining patterns of species' edaphic associations: sandstone specialists would have a competitive advantage over either alluvial specialists or edaphic generalists on the sandstone soil type, particularly during drought periods.

Sepilok frequently has short dry periods lasting 12 months and occasional severe droughts lasting 5-6 months (Walsh 1996). During these periods, soil water availability may decrease substantially, particularly on the sandy ridges. Such droughts have been found to impact tree and sapling survival significantly in Northwestern Borneo (Nakagawa et al. 2000, Delissio and Primack 2003, Potts 2003). Although some canopy leaf loss may occur during severe dry periods (Walsh and Newbery 1999), none of the forest types in Borneo are drought deciduous. Therefore adaptations allowing for some level of drought tolerance could provide a definite advantage during dry periods. Nakagawa et al. (2000) found similar elevated tree mortality rates between valleys and ridges at Lambir, Sarawak, during the 19971998 El Niño-associated drought, despite the greater soil water shortage undoubtedly experienced by trees occurring on the ridge tops. Gibbons and Newbery (2002) examined leaf water potentials in one ubiquitous and one ridge specialist at Danum Valley, Sabah, and found that the ridge specialist maintained much higher (i.e., less negative) leaf water potentials during both drought and nondrought periods. Lower leaf water potentials were suggested to induce embolism and cavitation and consequently increase mortality in the ubiquitous species during drought (Gibbons and Newbery 2002). These findings suggest that species not associated with the drier ridge top environments are more sensitive to drought. At SFR, sandstone species likely experience acute water shortage during drought as a result of higher root length density (C. Maycock, unpublished data), and thus greater competition for soil resources, in addition to lower soil water storage in the sandstone environment (Dent 2004). Without evolved mechanisms for more conservative water use, saplings would be at risk of enhanced mortality during drought periods. The present study indicates a physiological mechanism by which sandstone specialists may withstand these dry spells.

\section{Nitrogen-use efficiency}

Photosynthetic nitrogen-use efficiency (PNUE) was lower for sandstone specialists than for alluvial spe- 
cialists or generalists. Several studies have shown that PNUE is often lower for species growing on less fertile sites (Reich et al. 1994, Ellsworth and Reich 1996) and that species favored in high nutrient environments tend to have higher PNUE (Poorter and Remkes 1990). The explanation generally given for this counterintuitive pattern is that species associated with resource-poor environments have lower SLA and/or longer leaf life spans. These traits are often associated with lower PNUE (Poorter and Remkes 1990, Poorter and Evans 1998, Wright and Cannon 2001) due to increased nitrogen allocation to nonphotosynthetic functions such as defensive compounds. PNUE can also vary as a result of (1) high resistances to $\mathrm{CO}_{2}$ diffusion, (2) reduced allocation of nitrogen to photosynthetic enzymes, or (3) inefficient allocation of nitrogen among photosynthetic enzymes (Field and Mooney 1986, Evans 1989). On the sandstone soil, both water and nutrient availability are lower than on the alluvial soil (Table 1). Given that the sandstone specialists show greater WUE, it is not surprising that there is a tradeoff evident in PNUE. Reductions in water loss through stomatal closure inevitably increase the resistance to $\mathrm{CO}_{2}$ diffusion, which often leads to decreased PNUE (Lloyd et al. 1992, Hikosaka et al. 1998, Wright et al. 2001). Photosynthetic nutrient-use efficiency does not necessarily correspond to whole-plant NUE; enhanced leaf longevity in sandstone species could potentially compensate for this over longer time periods (Field and Mooney 1986, Reich et al. 1995). However, a related study found no consistent difference in average leaf lifespan between the sandstone and alluvial specialist pairs included in this study (J. L. Baltzer and S. C. Thomas, unpublished manuscript). It is interesting to note the large acclimatory shift in PNUE of the sandstone specialists when grown on the alluvium. These shifts suggest that the sandstone specialists were capable of increased PNUE when water availability was greater. However, sandstone specialists had consistently lower $A_{\max }$ than alluvial specialists regardless of soil type, which would likely act to decrease their competitive ability on the more resource-rich soil type.

\section{Light}

The light environment had large effects on $A_{\max }, R_{\mathrm{d}}$, and $g_{\mathrm{s}}$ in comparisons of gap and understory environments (Table 3) but was not able to explain differences in these traits between species associated with the two soil types. Species used in the RTE differed in their light response, with sandstone specialists exhibiting lower $A_{\max }$ regardless of the soil type on which they were grown. This indicates an inherent difference in the potential carbon gain and is consistent with the idea that plants characteristic of low-resource environments share a common suite of conservative traits that include lower photosynthetic and growth rates (reviewed in Chapin et al. 1993). Comparative studies have commonly found a close relationship between light avail- ability and $A_{\max }$ (Thomas and Bazzaz 1999, Givnish et al. 2004) and light availability and $R_{\mathrm{d}}$ (Fredeen and Field 1991, Lusk and Reich 2000). If light availability were the main resource influencing physiological patterns, it should predict both $A_{\max }$ and $R_{\mathrm{d}}$ regardless of soil type. This was not the case; $A_{\max }$ and $R_{\mathrm{d}}$ decreased for all RTE species when grown on the sandstone soil in the gaps, despite saturating light levels on both soil types. Additionally, there was a trend toward lower $A_{\max }$ in the sandstone understory compared to the alluvial understory, in spite of lower light availability in the latter. These results indicate that light was not driving the soil type-related differences in $A_{\max }$ and $R_{\mathrm{d}}$. However, estimations of whole-plant light compensation points provide evidence of greater light requirements in the sandstone specialists (J. L. Baltzer and S. C. Thomas, unpublished manuscript). This could account for enhanced mortality of sandstone specialists when grown in the alluvial understory (Nilus 2004) where light availability is more limiting, and thus provide a potential mechanism by which sandstone specialists are excluded from the alluvial forests.

\section{Soil nutrients}

The present study demonstrates important differences in water-use efficiency, distinguishing between sandstone specialists on the one hand and alluvial specialists and generalist species on the other. Soil nutrient amendment, however, had no effect on the physiological traits measured. This is not to say that the low availability of soil nutrients on the sandstone soil type is not playing an important role in forest dynamics at SFR. Moderate growth responses to fertilization in the gaps were evident on the sandstone soil type where nutrient availability is lowest (Nilus 2004). The discrepancy between physiological and growth responses may be attributable to a couple of factors. First, plants commonly alter allocation patterns with resource availability (Chapin 1980, Aerts et al. 1991), and it may be that with increased nutrient availability saplings were able to shift allocation patterns to favor aboveground biomass production. In this case, shifts in allocation could result in increased biomass production with no corresponding changes in physiological parameters. Growth responses to fertilization were most evident in terms of leaf production, suggesting that changes in allocation rather than leaf-level physiology may be driving other growth responses to fertilization (Nilus 2004). Alternatively, it is possible that there was some initial, short-lived physiological response to fertilization that our measurements failed to capture, but that could have resulted in enhanced growth in the high light-high nutrient treatment that would then have been compounded during the exponential growth phase of seedlings. It is also likely that resource limitation differs temporally such that there is a chronic limitation of nutrients on the sandstone soil type but that regular dry spells result in periods of strong water limitation. Without water con- 
servation strategies, survival during these dry times could be difficult on the sandstone soil type.

\section{Conclusions: the role of the resource-use efficiency hypothesis in explaining edaphic specialization}

The reciprocal transplant experiment on which this study is (in part) based was initially motivated by the hypothesis that biotic interactions drive the dramatic patterns of edaphic specialization commonly seen in the diverse forests of North Borneo. However, little difference was found between specialist species in herbivory rates, damage, or herbivore communities when grown together on either soil type at SFR (Eichhorn 2003). In contrast, recent work by Fine et al. (2004) in the Peruvian Amazon strongly implicates the importance of herbivory in maintaining edaphic specialization. Taken together, these studies suggest that mechanisms for habitat association maintenance may differ among tropical forests. Our results suggest that water-use efficiency is a critical factor maintaining sandstone specialization at SFR; however, critical questions remain regarding both alluvial specialization and generalist species. What limits sandstone species on alluvial soils? One possibility is that sandstone specialists show higher light requirements (J. L. Baltzer and S. C. Thomas, unpublished manuscript); alternatively, alluvial soils receive frequent freshwater flooding, and soil hypoxia may be important (cf. Silver et al. 1999). Finally, what factors differentiate between alluvial specialists and generalist species? Generalist species commonly comprise between 40 to $60 \%$ of tree species in tropical forests, yet studies examining habitat specialization have tended only to examine edaphic specialists (e.g., Itoh 1995, Fine et al. 2004, Palmiotto et al. 2004). Given their ecological importance, detailed investigations of the mechanisms maintaining high proportions of edaphic generalists in tropical rainforests are also warranted.

\section{ACKNOWLEDGMENTS}

We thank the Economic Planning Unit of the Prime Minister's Department and FRC, Sepilok, for permission to conduct research at SFR. We are also very grateful to Kalan Ickes for RTE establishment and direction, Colin Maycock for logistical support at SFR, Daisy Dent for soil nutrient and water availability data and many useful discussions, Andrew Spring and David and Rineson Yudat for field assistance, Deborah Tam and Yuan-Xin Teng for help with leaf nutrient analysis, Vic Timmer for generous use of laboratory facilities and helpful analytical advice, and Rowan Sage for comments and suggestions that strengthened the manuscript. We also thank Cam Webb, Rebecca Montgomery, and Nick Brown for critical reviews of earlier versions of the manuscript. Martin Lechowicz contributed substantially to the final version of this manuscript through his thorough, critical, and thoughtful editorial comments. This work was funded by the British Ecological Society and the Natural Science and Engineering Research Council of Canada.

\section{Literature Cited}

Aerts, R., R. G. A. Boot, and P. J. M. Vanderaart. 1991. The relation between above- and belowground biomass allo- cation patterns and competitive ability. Oecologia 87:551559.

Ashton, P. S. 1969. Speciation among tropical forest trees: some deductions in the light of recent evidence. Biological Journal of the Linnean Society 1:155-196.

Baillie, I. C., P. S. Ashton, M. N. Court, J. A. R. Anderson, E. A. Fitzpatrick, and J. Tinsley. 1987. Site characteristics and the distribution of tree species in mixed dipterocarp forest on tertiary sediments in Central Sarawak, Malaysia. Journal of Tropical Ecology 3:201-220.

Becker, P., P. E. Rabenold, J. R. Idol, and A. P. Smith. 1988. Water potential gradients for gaps and slopes in a Panamanian tropical moist forest's dry season. Journal of Tropical Ecology 4:173-184.

Bloom, A. J., F. S. Chapin, III, and H. A. Mooney. 1985. Resource limitation in plants-an economic analogy. Annual Review of Ecology and Systematics 16:363-392.

Caley, M. J., and P. L. Munday. 2003. Growth trades off with habitat specialization. Proceedings of the Royal Society of London Series B-Biological Sciences 270:S175-S177.

Chapin, F. S., III. 1980. The mineral nutrition of wild plants. Annual Review of Ecology and Systematics 11:233-260.

Chapin, F. S., III, K. Autumn, and F. Pugnaire. 1993. Evolution of suites of traits in responses to environmental stress. The American Naturalist 142:S78-S92.

Coley, P. D., and J. A. Barone. 1996. Herbivory and plant defenses in tropical forests. Annual Review of Ecology and Systematics 27:305-335.

Connell, J. H. 1971. On the role of natural enemies in preventing competitve exclusion in some marine animals and in rain forest trees. In P. J. den Boer and G. R. Gradwell, editors. Proceedings of the Advanced Study Institute. On dynamics of numbers in populations. Centre for Agricultural Publishing, Oosterbeek, The Netherlands.

Davies, S. J., P. A. Palmiotto, P. S. Ashton, H. S. Lee, and J. V. Lafrankie. 1998. Comparative ecology of 11 sympatric species of Macaranga in Borneo: tree distribution in relation to horizontal and vertical resource heterogeneity. Journal of Ecology 86:662-673.

Delissio, L. J., and R. B. Primack. 2003. The impact of drought on the population dynamics of canopy-tree seedlings in an aseasonal Malaysian rain forest. Journal of Tropical Ecology 19:489-500.

Dent, D. 2004. The mechanistic basis of habitat specialisation in dipterocarps. Dissertation. University of Aberdeen, Aberdeen, UK.

Dewitt, T. J., A. Sih, and D. S. Wilson. 1998. Costs and limits of phenotypic plasticity. Trends in Ecology and Evolution 13:77-81.

Dickie, I. A., R. T. Koide, and K. C. Steiner. 2002. Influences of established trees on mycorrhizas, nutrition, and growth of Quercus rubra seedlings. Ecological Monographs 72: 505-521.

Eichhorn, M. P. 2003. Insect herbivory and the regeneration of dipterocarp seedlings in a Malaysian rainforest. Dissertation. University of Leeds, Leeds, UK.

Ellsworth, D. S., and P. B. Reich. 1996. Photosynthesis and nitrogen in five Amazonian tree species during early secondary succession. Ecology 77:581-594.

Evans, J. R. 1989. Photosynthesis and nitrogen relationships in leaves of $\mathrm{C}_{3}$ plants. Oecologia 78:9-19.

Falster, D. S., D. I. Warton, and I. J. Wright. 2003. (S)MATR: standardised major axis tests and routines. Version 1.0 $\langle$ http://www.bio.mq.edu.au/ecology/SMATR $\rangle$

Farquhar, G. D., J. R. Ehleringer, and K. T. Hubick. 1989. Carbon isotope discrimination and photosynthesis. Annual Review of Plant Physiology and Plant Molecular Biology 40:503-537.

Farquhar, G. D., M. H. O’Leary, and J. A. Berry. 1982. On the relationship between carbon isotope discrimination and 
the intercellular carbon dioxide concentration in leaves. Australian Journal of Plant Physiology 9:121-137.

Felsenstein, J. 1985. Phylogenies and the comparative method. American Naturalist 125:1-15.

Field, C., J. Merino, and H. A. Mooney. 1983. Compromises between water-use efficiency and nitrogen-use efficiency in five species of California evergreens. Oecologia 60:384389.

Field, C., and H. A. Mooney. 1986. The photosynthesisnitrogen relationship in wild plants. Pages $25-55$ in T. J. Givnish, editor. On the economy of form and function. Cambridge University Press, Cambridge, UK.

Fine, P. V. A., I. Mesones, and P. D. Coley. 2004. Herbivores promote habitat specialization by trees in Amazonian forests. Science 305:663-665.

Fox, J. E. D. 1973. Kabili-Sepilok Forest Reserve. Borneo Literature Bureau, Kuching, Sarawak.

Fredeen, A. L., and C. B. Field. 1991. Leaf respiration in Piper species native to a Mexican rain forest. Physiologia Plantarum 82:85-89.

Futuyma, D. J., and G. Moreno. 1988. The evolution of ecological specialization. Annual Review of Ecology and Systematics 19:207-233.

Gartlan, J. S., D. M. Newbery, D. W. Thomas, and P. G. Waterman. 1986. The influence of topography and soil phosphorus on the vegetation of Korup Forest Reserve, Cameroon. Vegetatio 65:131-148.

Gibbons, J. M., and D. M. Newbery. 2002. Drought avoidance and the effect of local topography on trees in the understory of a Bornean lowland rain forest. Plant Ecology 164: $1-18$

Givnish, T. J., R. A. Montgomery, and G. Goldstein. 2004 Adaptive radiation of photosynthetic physiology in the Hawaiian lobeliads: light regimes, static light responses, and whole-plant compensation points. American Journal of Botany 91:228-246.

Grubb, P. J. 1977. The maintenance of species richness in plant communities: the importance of the regeneration niche. Biological Reviews 52:107-145.

Gunatilleke, C. V. S., I. A. U. N. Gunatilleke, G. A. D. Perera, D. F. R. P. Burslem, P. M. S. Ashton, and P. S. Ashton. 1997. Responses to nutrient addition among seedlings of eight closely related species of Shorea in Sri Lanka. Journal of Ecology 85:301-311.

Harms, K. E., R. Condit, S. P. Hubbell, and R. B. Foster. 2001. Habitat associations of trees and shrubs in a 50-ha neotropical forest plot. Journal of Ecology 89:947-959.

Hikosaka, K., Y. T. Hanba, T. Hirose, and I. Terashima. 1998. Photosynthetic nitrogen-use efficiency in leaves of woody and herbaceous species. Functional Ecology 12:896-905.

Hubbell, S. P. 2001. The unified theory of biodiversity and biogeography. Princeton University Press, Princeton, New Jersey, USA.

Hubbell, S. P., and R. B. Foster. 1986. Biology, chance and history and the structure of tropical rain forest tree communities. In J. Diamond and T. J. Case, editors. Community ecology. Harper and Row, New York, New York, USA.

Itoh, A. 1995. Effects of forest floor environment on germination and seedling establishment of two Bornean rainforest emergent species. Journal of Tropical Ecology 11: 517-527.

Itoh, A., T. Yamakura, T. Ohkubo, M. Kanzaki, P. A. Palmiotto, J. V. LaFrankie, P. S. Ashton, and H. S. Lee. 2003. Importance of topography and soil texture in the spatial distribution of two sympatric dipterocarp trees in a Bornean rainforest. Ecological Research 18:307-320.

Janzen, D. H. 1970. Herbivores and number of tree species in tropical forests. American Naturalist 104:501-528.

Lambers, H., and H. Dijkstra. 1987. A physiological analysis of genetic variation in relative growth rate: Can growth rate confer ecological advantage? Pages 237-252 in J. Van Andel, J. P. Bakker, and R. W. Snaydon, editors. Disturbance in grasslands: causes, effects and processes. Dr. Junk, Dordrecht, The Netherlands.

Lambers, H., R. K. Szaniawski, and R. deVisser. 1983. Respiration for growth, maintenance and ion uptake. An evaluation of concepts, methods, values and their significance. Physiologia Plantarum 58:556-563.

Latham, R. E. 1992. Co-occuring tree species change rank in seedling performance with resources varied experimentally. Ecology 73:2129-2144.

Lee, L. S., and I. J. Alexander. 1996. The dynamics of ectomycorrhizal infection of Shorea leprosula seedlings in Malaysian rain forests. New Phytologist 132:297-305.

Lescure, J. P., and R. Boulet. 1985. Relationships between soil and vegetation in a tropical rain forest in French Guiana. Biotropica 17:155-164.

Leverenz, J. W. 1988. The effects of illumination sequence, $\mathrm{CO}_{2}$ concentration, temperature and acclimation on the convexity of the photosynthetic light response curve. Physiologia Plantarum 74:332-341.

Lloyd, J., J. P. Syvertson, P. E. Kriedmann, and G. D. Farquhar. 1992. Low conductances for $\mathrm{CO}_{2}$ diffusion from stomata to the sites of carboxylation in leaves of woody species. Plant Cell and Environment 15:873-899.

Lusk, C. H., and F. Matus. 2000. Juvenile tree growth rates and species sorting on fine-scale soil fertility gradients in a Chilean temperate rain forest. Journal of Biogeography 27:1011-1020.

Lusk, C. H., and P. B. Reich. 2000. Relationships of leaf dark respiration with light environment and tissue nitrogen content in juveniles of 11 cold-temperate tree species. Oecologia 123:318-329.

Moad, A. S. 1992. Dipterocarp juvenile growth and understory light availability in Malaysian tropical forest. Dissertation. Harvard University, Cambridge, Massachusetts, USA.

Nakagawa, M., et al. 2000. Impact of severe drought associated with the 1997-1998 El Nino in a tropical forest in Sarawak. Journal of Tropical Ecology 15:355-367.

Nilus, R. 2004. Effect of edaphic variation on forest structure, dynamics, diversity and regeneration in a lowland tropical rain forest in Borneo. Dissertation. University of Aberdeen, Aberdeen, UK.

Ogren, E., and J. R. Evans. 1993. Photosynthetic light response curves I. The influence of $\mathrm{CO}_{2}$ partial pressure and leaf inversion. Planta 189:182-190.

Palmiotto, P. A., S. J. Davies, K. A. Vogt, M. S. Ashton, D J. Vogt, and P. S. Ashton. 2004. Soil-related habitat specialization in dipterocarp rain forest tree species in Borneo. Journal of Ecology 92:609-623.

Poore, M. E. D. 1968. Studies in Malaysian rain forest. I. Forest on Triassic sediments in Jengka Forest Reserve. Journal of Ecology 56:143-196.

Poorter, H., and J. R. Evans. 1998. Photosynthetic nitrogenuse efficiency of species that differ inherently in specific leaf area. Oecologia 116:26-37.

Poorter, H., and C. Remkes. 1990. Leaf area ratio and net assimilation rate of 24 wild species differing in relative growth rate. Oecologia 83:553-559.

Potts, M. D. 2003. Drought in a Bornean everwet rain forest. Journal of Ecology 91:467-474.

Proctor, J. 2003. Vegetation and soil and plant chemistry on ultramafic rocks in the tropical Far East. Perspectives in Plant Ecology 6:105-124.

Proctor, J., J. M. Andersen, S. C. L. Fogden, and H. W. Vallack. 1988. Ecological studies in four contrasting lowland rainforests in Gunung Mulu National Park, Sarawak: II. Litterfall, litter standing crop and preliminary observations on herbivory. Journal of Ecology 71:261-283. 
Reich, P. B., D. S. Ellsworth, and C. Uhl. 1995. Leaf carbon and nutrient assimilation and conservation in species of differing successional status in an oligotrophic Amazonian forest. Functional Ecology 9:65-76.

Reich, P. B., M. B. Walters, D. S. Ellsworth, and C. Uhl. 1994. Photosynthesis-nitrogen relationships in Amazonian tree species. I. Patterns among species and communities. Oecologia 104:24-30.

Reich, P. B., I. J. Wright, J. Cavender-Bares, J. M. Craine, J. Oleksyn, M. Westoby, and M. B. Walters. 2003. The evolution of plant functional variation: traits, spectra, and strategies. International Journal of Plant Sciences 164:S143S164.

Relyea, R. A. 2002. Costs of phenotypic plasticity. The American Naturalist 159:272-282.

Ryan, M. G. 1995. Folar maintenance respiration of subalpine and boreal trees and shrubs in relation to nitrogen content Plant Cell and Environment 18:765-772.

Schuman, G. E., M. A. Stanley, and D. Knudsen. 1973. Automated total nitrogen analysis of soil and plant samples Soil Science Society of America Proceedings 37:480-481.

Silver, W. L., A. E. Lugo, and M. Keller. 1999. Soil oxygen availability and biogeochemistry along rainfall and topographic gradients in upland wet tropical forest soils. Biogeochemistry 44:301-328.

Thomas, S. C. 2003. Comparative biology of tropical trees: a perspective from Pasoh. Pages 171-194 in T. Okuda, N. Manokaran, Y. Matsumoto, K. Niiyama, S. C. Thomas, and P. S. Ashton, editors. Ecology of a lowland rain forest in Southeast Asia. Springer-Verlag, Tokyo, Japan.

Thomas, S. C., and F. A. Bazzaz. 1999. Asymptotic height as a predictor of photosynthetic characteristics in Malaysian rain forest trees. Ecology 80:1607-1622.

Van Tienderen, P. H. 1991. Evolution of generalists and specialists in spatially heterogeneous environments. Evolution 45:1317-1331.
Walsh, R. P. D. 1996. Drought frequency changes in Sabah and adjacent parts of northern Borneo since the late nineteenth century and possible implications for tropical rain forest dynamics. Journal of Tropical Ecology 12:385-407.

Walsh, R. P. D., and D. M. Newbery. 1999. The ecoclimatology of Danum, Sabah, in the context of the world's rainforest regions, with particular reference to dry periods and their impact. Philosophical Transactions of the Royal Society of London Series B-Biological Sciences 354:18691883.

Warton, D., and N. C. Weber. 2002. Common slope tests for bivariate structural relationships. Biometrical Journal 44: 161-174.

Webb, C. O., and D. R. Peart. 2000. Habitat associations of trees and seedlings in a Bornean rain forest. Journal of Ecology 88:464-478.

Whitmore, T. C., and N. D. Brown. 1996. Dipterocarp seedling growth in rain forest canopy gaps during six and a half years. Philosophical Transaction of the Royal Society of London 351:1195-1203.

Wills, C., R. Condit, R. B. Foster, and S. P. Hubbell. 1997. Strong density- and diversity-related effects help to maintain tree species diversity in a neotropical forest. Proceedings of the National Academy of Sciences of the United States of America 94:1252-1257.

Wright, I. J., and K. Cannon. 2001. Relationships between leaf lifespan and structural defenses in a low nutrient, schlerophyll flora. Functional Ecology 15:351-359.

Wright, I. J., P. B. Reich, and M. Westoby. 2001. Strategy shifts in leaf physiology, structure and nutrient content between species of high- and low-rainfall and high- and lownutrient habitats. Functional Ecology 15:423-434.

Wright, I. J., P. B. Reich, and M. Westoby. 2003. Least-cost input mixtures of water and nitrogen for photosynthesis. American Naturalist 161:98-111.

\section{APPENDIX}

A table containing physiological parameters for species used in the survey study is available in ESA's Electronic Data Archive: Ecological Archives E086-167-A1. 